\title{
Seismic behaviour of geotechnical structures
}

\author{
Stefania Sica, Filippo Santucci de Magistris and Filippo Vinale \\ Dipartimento di Ingegneria Geotecnica, Polo delle Scienze e delle Tecnologie, \\ Università degli Studi di Napoli «Federico II», Napoli, Italy
}

\begin{abstract}
This paper deals with some fundamental considerations regarding the behaviour of geotechnical structures under seismic loading. First a complete definition of the earthquake disaster risk is provided, followed by the importance of performing site-specific hazard analysis. Then some suggestions are provided in regard to adequate assessment of soil parameters, a crucial point to properly analyze the seismic behaviour of geotechnical structures. The core of the paper is centered on a critical review of the analysis methods available for studying geotechnical structures under seismic loadings. All of the available methods can be classified into three main classes, including the pseudo-static, pseudo-dynamic and dynamic approaches, each of which is reviewed for applicability. A more advanced analysis procedure, suitable for a so-called performance-based design approach, is also described in the paper. Finally, the seismic behaviour of the El Infiernillo Dam was investigated. It was shown that coupled elastoplastic dynamic analyses disclose some of the important features of dam behaviour under seismic loading, confirmed by comparing analytical computation and experimental measurements on the dam body during and after a past earthquake.
\end{abstract}

Key words case histories - dams - f.e.m. - seismic design - soil dynamics

\section{Introduction}

On December 3rd and 4th 2001, the «Earth Sciences and Natural Disaster Prevention. A Japan-Italy joint meeting in year 2001» was held in Kyoto and Kobe.

Session III of the meeting was devoted to «Civil Engineering Aspects of Seismic and Volcanic Risk Prevention». This paper summarizes the contribution from the Department

Mailing address: Dr. Filippo Santucci de Magistris, Dipartimento di Ingegneria Geotecnica, Polo delle Scienze e delle Tecnologie, Università degli Studi di Napoli «Federico II», Via Claudio 21, 80125 Napoli, Italy; e-mail: filsantu@unina.it of Geotechnical Engineering, University of Naples (Italy), at this session of the conference.

After an introduction to the problem of seismic risk evaluation, the paper focuses on a few considerations of the geotechnical site characterization, including some notes on soil behaviour under cyclic loading and measurement of soil parameters. Then, some analysis methods that are currently available in literature to study the seismic performance of earth structures will be assessed. Finally the dynamic behaviour of an earth dam will be presented as a typical, though complex, case history. Since the «Seismic Behaviour of Geotechnical Structures» theme is extremely broad, only some of the previously mentioned topics will be extensively treated in the next pages. More extensive details can be found in the references and in the technical literature for the specific topics. 


\section{Risk analysis}

For over forty years, since the devastating 1964 Alaska (U.S.) and Niigata (Japan) earthquakes occurred, considerable progress has been made in the field of soil dynamics and geotechnical earthquake engineering. Significant development has been achieved in forecasting the strong ground motion after appropriate seismic hazard analysis, in understanding the mechanical behaviour of geomaterials, in evaluating the ground response during an earthquake and in modeling structures response under seismic loading. These studies provide an important contribution to the general field of seismic risk analysis.

Seismic risk studies are conventionally based on the analysis of a single component of risk, often directed at a particular region. More complete analyses require the definition of all factors on which an area's earthquake disaster risk depends. Furthermore, the risk level in a particular region should be periodically updated.

In general, disaster could be considered not only a function of the expected physical impact of future earthquakes, but also of the capacity of the affected area to sustain that impact, as well as the implications on local economic and social affairs (Davidson, 1997). As a matter of fact, while people may not be able to stop the occurrence of earthquakes, they might be able to regulate some of the other contributing factors (e.g., resources available for emergency response and recovery, vulnerability of the infrastructure), thereby reducing the frequency and severity of earthquake-induced damage. It should be considered also that worldwide earthquake disaster risk has grown significantly over the past decades due to exploding populations in seismic regions, unimpeded urbanization, and the increasingly interconnected and internally complex urban plan of most existing cities.

Therefore, if in a conventional perspective, any risk, including seismic risk, is a convolution of exposure, hazard, and vulnerability, a more extended definition might also include other factors such as external context (political and economic) and emergency response and recovery capability. Figure 1 summarizes a proposed definition of earthquake disaster risk after Davidson (1997). In this figure, hazard represents the geological phenomena that act as initiating events of an earthquake disaster. Earthquake hazards include not only ground shaking but also collateral damage such as liquefaction, landslides, tsunamis, ground rupture and subsidence. Exposure includes list of everything that is subject to the physical demands imposed by the hazard. Vulnerability describes how easily and how severely physical infrastructures, population, economy, and social-political system can be affected by an earthquake. External context describes how damage to a city affects people and activities outside the city. It incorporates the reality that, depending on a city's prominence with respect to economics, transportation, politics, and culture, damage to certain cities may have more far-reaching effects than damage to

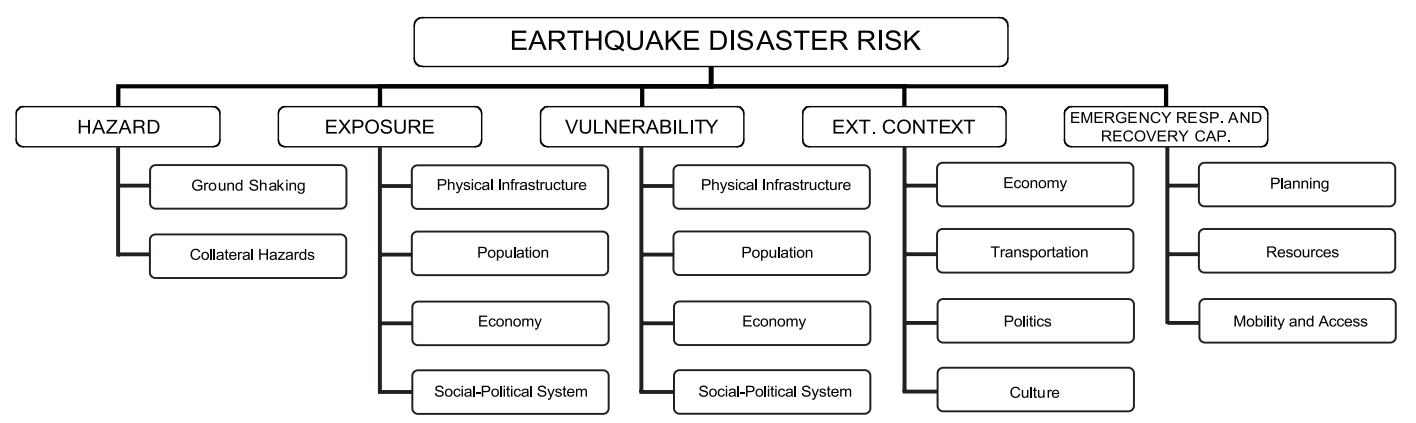

Fig. 1. Factors contributing to the definition of earthquake disaster risk (after Davidson, 1997). 
others. Emergency response and recovery capability describe how effectively and efficiently a community can recover from shortand long-term impact through formal, organized activities.

While we have little control over seismic hazard, full awareness of structural and environmental seismic vulnerability, will help seismic engineers concentrate their efforts on reducing structural and environmental weaknesses. To help reach this objective, the seismic behaviour of structures, including geotechnical structures, should be fully understood.

\section{The role of geotechnical engineers}

From the previous paragraph it clearly emerges that seismic risk analysis is a typical multidisciplinary study. While the obvious role of a seismic geotechnical engineer is that of detecting and examining the performance of geotechnical structures under dynamic loading, his «cultural» responsibility in the evaluation of free-field ground response $(*)$ is essential too. Here, it is worth remembering that ground response analyses are used to predict ground surface motion for the development of design response spectra, to evaluate liquefaction hazards or landslide occurrences and to determine the earthquake-induced forces on civil structures. Thus, an essential responsibility of an earthquake geotechnical engineer consists of detecting ground surface motion that is strongly influenced by the soil strata that might lie above the bedrock. This influence, as well as the general behaviour of earth structures, cannot be fully understood without: 1) proper knowledge of the subsoil stratigraphy; 2) mechanical behaviour of any subsoil strata and of the materials constituting the earth structure, including a proper knowledge of experimental techniques, and 3) proper use of numerical models able to simulate the subsoil

(*) Detailed explanations on the evaluation of ground motion during an earthquake can be found in Kramer (1996). response, the geotechnical structure response, as well as their interaction.

Points (2) and (3) have some peculiarities that will be briefly emphasized in the following paragraphs. Point (3) will be developed with the aim of detecting the seismic behaviour of geotechnical structures.

\section{Soil behaviour under cyclic loading}

The effect of earthquake loads on a soil element can be represented by a complex shear stress time history $\tau(t)$, acting after a previous loading history. Depending on the level of the considered earthquake motion and the dynamic properties of the soil-structure system, the soil shear strain level induced by the seismic event can vary. Consequently, the soil should be characterized by models of different complexity. Typical gross distinctions can be made between soil behaviour at pre-failure and at failure conditions. In the first case, further distinctions are made among the so-called «small-strain region», the «medium strain region» and the «large strain region». Distinction can be easily understood by considering the schematic soil behaviour as reported in fig. 2, which shows typical relationships existing between shear stiffness or damping ratio and the shear strain level. At small strains, soil stiffness and damping ratio attained their maximum and minimum values, respectively. Soil response can be adequately represented by a linear model.

At medium strains, soil shows a clear nonlinear behaviour but the response under cyclic loading is stable (i.e. no plastic volumetric strains or pore water pressure is detected). In this strain range soil behaviour can be represented by linearly equivalent models.

Finally, at large strains shear-volumetric coupling is apparent and the effect of the number of cyclic loadings cannot be neglected. In this case, elastoplastic effective stress models could be opportunely used to simulate soil behaviour. Several parameters affect both initial shear strain and damping ratio and their strain dependency. Readers can refer to, for instance, D'Onofrio and Silvestri (2001) for some information of this topic. 


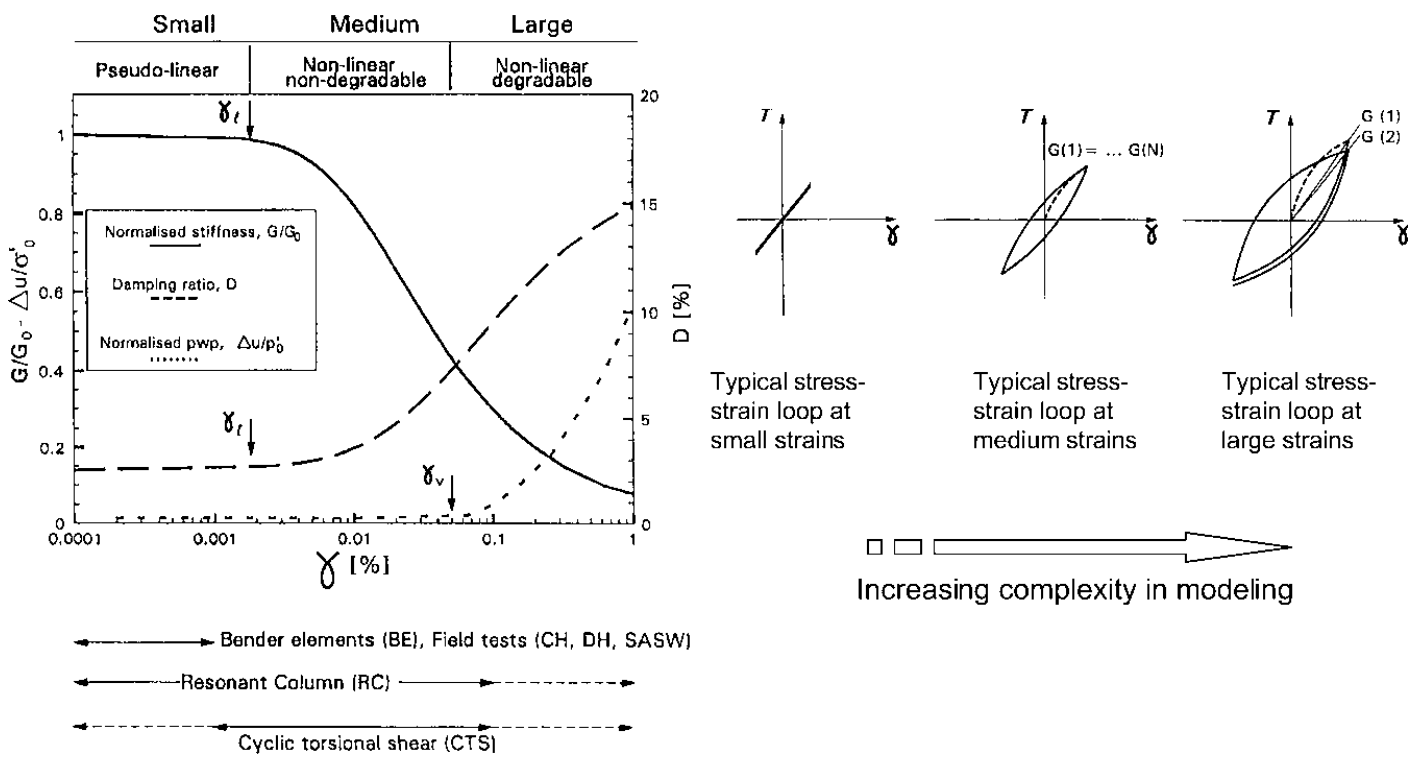

Fig. 2. Typical variation of the soil response under cyclic loading at increasing strain level in terms of shear modulus and damping and stress-strain loops.

\section{Measurement of soil parameters}

In geotechnical engineering design practice, field and laboratory investigation have advantages and disadvantages. Therefore, it might be useful to employ both in situ and laboratory measurement procedures to obtain a proper soil characterization. As shear modulus $G_{0}$ and damping ratio $D_{0}$ at small strain levels might be affected by sample disturbance, less so in the case of soil non-linearity, the strain dependence soil stiffness might be evaluated through

$$
G(\gamma)=\left(G_{0}\right)_{\text {field }} \cdot\left[\frac{G(\gamma)}{G_{0}}\right]_{\text {lab }}
$$

and the strain dependency of soil damping by

$$
D(\gamma)=\left(D_{0}\right)_{\text {field }}+[\bar{D}(\gamma)]_{\mathrm{lab}} .
$$

In the previous equations $\left(G_{0}\right)_{\text {field }}$ and $\left(D_{0}\right)_{\text {field }}$ are preferably evaluated by measurement of in situ shear wave velocity; $G(\gamma) / G_{0}$ should be determined by laboratory tests, as should $\bar{D}(\gamma)$. The latter represents the measured damping ratio scaled to the relevant small strain value $D_{0}$.

As the scope here is not to detail experimental techniques and procedures, a list of the most common techniques is reported in table I.

Some other special apparatuses not listed in table I have been developed at some Universities and Research Centers (refer to, for instance, http:/ /www.iis.u-tokyo.ac.jp/ hayanodex2.html; http:/ /geotle.t.u-tokyo.ac.jp/; http://www.entpe.fr/ Prive/index-recherche.htm). However, such machines are still prototypes and not widely available.

In situ soil tests for earthquake geotechnical engineering are typically geophysical, including surface tests such as Spectral Analysis Surface Waves (SASW), and borehole tests such as DownHole (DH) test and Cross-Hole (CH) test.

Laboratory tests can be categorized as either:

1) Static tests, in which stress-strain properties derive from the direct measure of stress and strain; or 
Table I. In situ and laboratory experimental techniques to obtain some relevant properties for analyzing the seismic behaviour of geotechnical structures (after International Navigation Association, 2001). In geotechnical earthquake engineering CPT and SPT should be properly used only providing empirical correlation with relevant soil properties.

\begin{tabular}{|c|c|c|c|c|c|c|c|c|c|}
\hline \multirow{2}{*}{\multicolumn{2}{|c|}{ Test class }} & \multirow{5}{*}{$\begin{array}{c}\text { Test type } \\
\text { SPT } \\
\text { CPT } \\
\text { Down-Hole }\end{array}$} & \multirow{7}{*}{$\begin{array}{c}\begin{array}{c}\text { Consolidation } \\
\text { stress state }\end{array} \\
\text { Lithostatic }\end{array}$} & \multirow{4}{*}{$\begin{array}{c}\text { Shear strain } \\
\quad \gamma \mathbb{F} \text { o }\end{array}$} & \multirow{4}{*}{$\begin{array}{l}\text { Frequency } \\
f[\mathrm{~Hz}]\end{array}$} & \multirow{4}{*}{$\begin{array}{c}\text { Stiffness } \\
\\
\begin{array}{l}N \rightarrow V_{s} \rightarrow G_{0} \\
q_{c} \rightarrow V_{s} \rightarrow G_{0}\end{array}\end{array}$} & \multirow[t]{4}{*}{ Damping } & \multicolumn{2}{|c|}{ Strength } \\
\hline & & & & & & & & & $F$ \\
\hline \multirow{5}{*}{ Field } & \multirow[b]{2}{*}{ Penetration } & & & & & & & $\phi^{\prime}$ & \\
\hline & & & & & & & & $\phi^{\prime}$ & $c_{u}$ \\
\hline & \multirow{3}{*}{ Geophysical } & & & \multirow{3}{*}{$<10^{-3}$} & \multirow{3}{*}{$10-100$} & $V_{S} \rightarrow G_{0}$ & - & & \\
\hline & & Cross-Hole & & & & $V_{s} \rightarrow G_{0}$ & possible & & \\
\hline & & SASW & & & & $V_{R} \rightarrow V_{S} \rightarrow G_{0}$ & - & & \\
\hline \multirow{5}{*}{ Laboratory } & \multirow{3}{*}{ Cyclic } & Triaxial & Axisymmetric & $>10^{-2}$ & $0.01-1$ & $q: \varepsilon_{a} \rightarrow E \rightarrow G$ & \multirow{3}{*}{$W_{D} / W_{s} \rightarrow D$} & \multicolumn{2}{|c|}{$q / \sigma_{r}^{\prime}: N_{c}$} \\
\hline & & Simple shear & Axisymmetric & $>10^{-2}$ & $0.01-1$ & $\tau: \gamma \rightarrow G$ & & \multicolumn{2}{|c|}{$\tau / \sigma_{v}^{\prime}: N_{c}$} \\
\hline & & $\begin{array}{c}\text { Torsional } \\
\text { shear }\end{array}$ & $\begin{array}{l}\text { Axisymmetric } \\
\text { or true triaxial }\end{array}$ & $10^{-4}-1$ & $0.01-1$ & $\tau: \gamma \rightarrow G_{0}, G$ & & & \\
\hline & \multirow{2}{*}{ Dynamic } & $\begin{array}{l}\text { Resonant } \\
\text { column }\end{array}$ & $\begin{array}{l}\text { Axisymmetric } \\
\text { or true triaxial }\end{array}$ & $10^{-4}-1$ & $>10$ & $f_{r} \rightarrow G_{0}, G$ & H.p., R.f. $\rightarrow D$ & & \\
\hline & & $\begin{array}{l}\text { Bender } \\
\text { elements }\end{array}$ & Axisymmetric & $<10^{-3}$ & $>100$ & $V_{s} \rightarrow G_{0}$ & & & \\
\hline
\end{tabular}

$V_{S}=$ shear wave velocity; $V_{R}=$ Rayleigh wave velocity; $f_{r}=$ resonant frequency; $H . p$. . $=$ half-power method; $R . f .=$ resonance factor method; $N=$ SPT blow count; $q_{c}=$ CPT tip resistance; $\phi^{\prime}=$ friction angle in effective stresses; $c_{u}=$ undrained shear strength; $C=$ coarse grained; $F=$ fine grained soils; $q / \sigma_{r}^{\prime}=$ deviator $/$ radial stress ratio; $\tau / \sigma_{v}^{\prime}=$ shear/vertical stress ratio; $N_{c}=$ number of cycles.

2) Dynamic tests, in which the soil properties are derived from a dynamic equilibrium analysis of a soil element.

Static tests usually include Cyclic Triaxial tests (CTX), Cyclic Simple Shear tests (CSS) and Cyclic Torsional Shear tests (CTS). Resonant Column tests (RC) and Bender Element tests (BE) are typically considered dynamic tests.

Choice of experimental technique for soil characterization is a matter of compromise between technical and economic factors.

As far as in situ tests are concerned, it is well known that the $\mathrm{CH}$ test is the most reliable, albeit most expensive, system for evaluating initial soil stiffness. The multi-receiver $\mathrm{CH}$ test also allows for the measurement of field small strain damping ratio $D_{0}$. On the other hand, multistation testing configuration for analyzing surface waves appears to be a promising, although complex, in situ experimental technique that provides not only the stiffness profile but also the damping ratio profile (Foti, 1999).
As for laboratory tests, sound laboratory practice in itself might be able to mitigate the influence of sample disturbance. A suitable reconsolidation technique up to the in situ stress state (that includes appropriate anisotropic reconsolidation stress-path and ageing time) can be, for instance, of some benefit to obtain more realistic subsequent stress-strain behaviour of soils (Vinale et al., 2000). For the resonant column tests, conventional interpretation criteria are based on the assumption that soil can be modeled as a linear visco-elastic medium, an idealization typically made in solving some boundary value problems in seismic geotechnical engineering. It is worth noting that linear viscoelasticity is insufficient for understanding some important features regarding time-dependent behaviour of geomaterials (see Tatsuoka et al., 2000), while new non-linear three-component rheology models have been proposed (Di Benedetto et al., 2002; Tatsuoka et al., 2002). In any case, time-dependency in the stress-strain be- 
haviour of soil should be strongly considered in designing any experiment involving geomaterials.

Recent developments in triaxial apparatuses allow stress-strain properties of soil to be obtained under a wide range of strain and strain rates (Tatsuoka et al., 1994; Santucci de Magistris et al., 1999). It must be emphasized, however, that only Young's soil modulus can be directly obtained from the triaxial apparatus, unless reliable radial strain measurements and a proper soil model are available. A relationship between Young's modulus and shear modulus is not easy to acquire, even in the case of undrained tests (Vinale et al., 2001).

In general, while the Resonant Column test (RC) is relatively common in Italy (Cavallaro et al., 2001), a recent survey shows that this apparatus has become less popular in Japan (Kuwano and Katagiri, 2001).

\section{Analysis methods}

Many approaches have been developed to analyze the seismic behaviour of geotechnical structures. They can be classified on several bases: geometry assigned to the soil-structure system (i.e. one-dimensional, two-dimensional, three-dimensional), constitutive model describing the material stress-strain response (i.e. linear elastic, non linear elastic, elastoplastic with or without hardening), the modeling of the interaction phenomena among different phases present in a soil (soil, water and air), the way in which the seismic loads are described (i.e. peak ground acceleration, response spectrum, acceleration time history). For the sake of simplicity, all the methods available in literature can be grouped into three main classes, including:

1) Simplified analyses, which allow for evaluating the safety factor of a soil-structure mass by simple global force equilibrium.

2) Simplified dynamic analyses, which provide the earthquake-induced displacement on the basis of an assumed failure mode of the soilstructure system.

3) Full dynamic analyses, in order to evaluate both magnitude of displacements and failure modes.
Until the Sixties, among the simplified analysis methods the pseudo-static approach represented the main tool used to assess the seismic safety of most geotechnical structures (retaining walls, embankments, earth dams, port structures). Nowadays this method is still widely used since it is imposed by several national regulations (in Italy, the D.M. 24/3/82) and because engineers have confidence in its use. Both the commercial codes that implement it and the quantitative definition of the required parameters are very simple.

In the pseudo-static approach, the dynamic inertia forces induced by an earthquake are considered static actions proportional to the soil mass by a seismic coefficient (fig. 3). The value of such a coefficient is determined on the basis of the expected peak ground acceleration in the area where the structure is located. National standards generally prescribe the seismic coefficient value according to the seismic category of the site.

In the case of retaining walls (gravity and sheet pile walls), the pseudo-static approach requires determination of both active and passive earth pressures. They are usually estimated using the Mononobe-Okabe equation (Mononobe, 1924; Okabe, 1924) obtained by modifying the Coulomb classical earth pressure solution to account for inertia forces.

One of the main limits of the pseudostatic method consists of considering the failure along a well-defined sliding surface as the only type of damage that an earth structure could suffer during an earthquake. This assumption could be reasonable in the case of retaining walls, but it might be misleading for other geotechnical structures. In the case of earth dams, for instance,

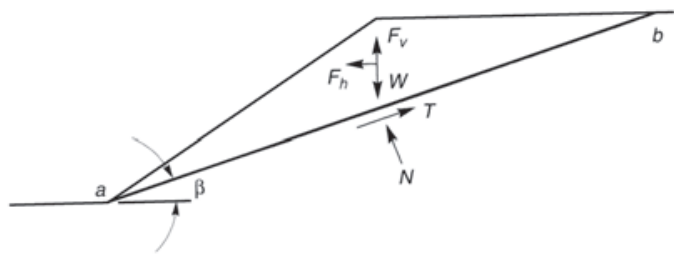

Fig. 3. Pseudostatic loads acting on a sliding mass. 
additional information is required about freeboard loss and safety against liquefaction or fracture of dam elements (core or filter) that assure water tightness. Literature documents many case histories of earth dams that failed either partially or totally during earthquakes, even if the pseudo-static approach had given a positive result about their seismic safety. Lower San Fernando Dam (Seed, 1979) and Hebgen Dam (Steinbrugge and Cloud, 1962) are two classic examples.

The simplified dynamic approach, first introduced by Newmark, still idealizes the soilstructure system as rigid blocks of soil and structural masses. Moreover, the method allows computation of the displacement of the sliding masses by integrating the acceleration time history overcoming the so-called critical acceleration, i.e. the threshold acceleration that causes the block to slide (fig. 4). The seismic safety of the earth structure is evaluated in terms of an acceptable permanent displacement rather than a factor of safety against global instability, as is typical in the pseudo-static approach. Simplified dynamic analyses, including the original Newmark method (Newmark, 1965) and the numerous Newmark-derived methods (i.e. Makdisi and Seed (1978) for embankments and earth dams; Yegian et al. (1991) for embankments; Franklin and Chang (1977) for dikes; Richards and Elms (1979) for gravity walls; Towahata and Islam (1987) for sheet pile walls; Steedman (1998) for gravity and sheet pile walls) can prove very useful when a performance-based design philosophy is likely to be adopted to overcome the limitations of conventional seismic design.

Full dynamic analysis directly models the overall soil-structure interaction problem, assuming that both soil and structure behave as continuum and deformable media. The spatial domain is discretized using a numerical technique (generally, finite element or finite difference methods) and the differential equation governing the boundary value problem is solved over the time or frequency domain. Since the solution in the frequency domain is admissible only when the material linearity hypothesis persists, it is worth noting that the solution over the time domain is mandatory when more
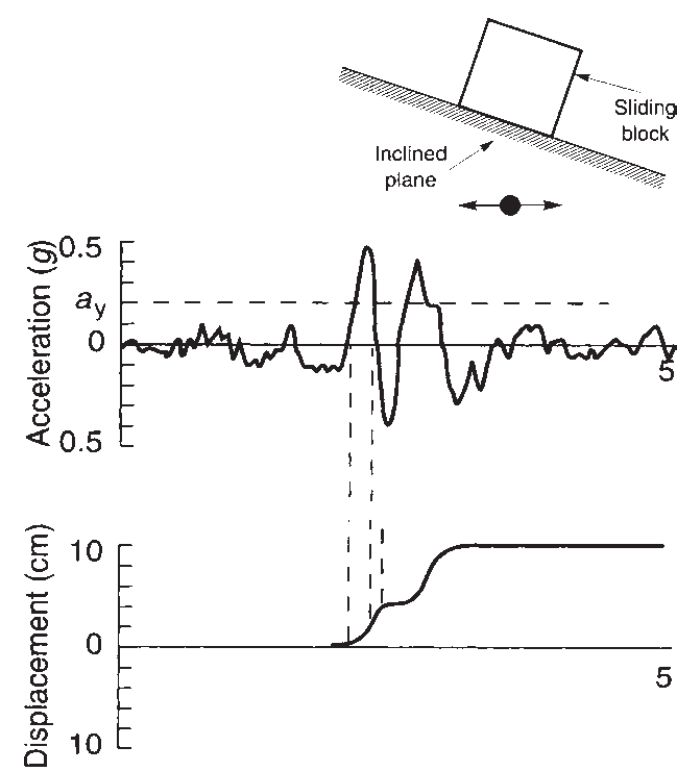

Time (s)

Fig. 4. Newmark sliding block approach

sophisticated constitutive models (inelastic or elastoplastic) are assumed for the soil-structure system. As discussed previously, the choice between a linear or non-linear material model depends on the expected level of earthquake motion relative to the elastic limit of the soilstructure system.

Inside the class of full dynamic analysis methods, a more detailed distinction can be made in describing the interaction among the different phases - air, water and soil skeleton - of the soil constituting the structure and its foundation. According to this point of view, the dynamic methods can be further classified as:

- one-phase or total stress approach;

- simplified two-phase or simplified effective stress;

- coupled two- or three-phase approaches.

In the one-phase approach the interaction among the soil phases is actually neglected, and the soil is assumed to be an equivalent monophase continuum governed by dynamic equilibrium equations, continuity equations and 
constitutive law. In particular, the constitutive law refers to the behavior of the whole soil skeletonpore fluid system. Inside this category, the equivalent linear procedure has been the most widely used technique for computing the dynamic response of soil deposits, embankments and soil-structure interaction. This approach is implemented in very popular codes, such as SHAKE (Schnabel et al., 1972), FLUSH (Lysmer et al., 1975) or QUAD-4 (Idriss et al., 1973). Notwithstanding the simplicity and popularity of the equivalent linear procedure, its main limitation lies in not providing any prediction of earthquake induced permanent displacements. As a matter of fact, the method is meaningless when higher strain levels are involved and permanent displacements should be forecast. Many attempts in literature to overcome this limitation of the equivalent linear method are documented (Seed, 1979).

In the simplified two-phase approaches, a semi-empirical law (excess pore water model) is introduced to evaluate the pore water pressure induced by cyclic shear stresses. This law links the excess pore water pressure to the number and amplitude of the applied deviatoric cyclic stresses (Martin et al., 1975; Finn and Bathia, 1981; Dobry et al., 1985; Matasovic and Vucetic, 1992, 1995). The effect of the excess pore water pressure is incorporated into the equivalent linear analysis or into a direct non-linear analysis by reducing the actual stiffness of the soil. Such an approach is implemented in computer codes as FLUSH-L (Ozutsumi et al., 2000) and TARA-3 (Finn et al., 1986).

In the coupled two-phase approaches the constitutive law refers only to the soil skeleton. To account for the presence of the pore fluid, the continuity equation of the water is incorporated as well. The stress-strain behaviour of the soil can be described by different constitutive laws according to the level of sophistication required: linear elastic, hypoelastic, elastoplastic with kinematic or combined hardening. In this category, the effective stress methods implementing elastoplastic models based on the concept of combined hardening (isotropic and kinematic) have proven very powerful in computing residual displacements and/or evaluating the structure response beyond the elastic strain level (Prevost,
1985; Muraleetharan et al., 1988; Iai et al., 1998; Benzenati, 1993; Sica et al., 2001). In the case of earth dams, for instance, these methods allow evaluation of the structure's safety against most types of earthquake-induced damage: freeboard loss, liquefaction due to excess pore water pressures and post seismic effects.

The choice of analysis approach should be based on the principle that structures requiring higher performance (structures with high exposure) should be designed/verified using more sophisticated methods. In light of this, simpler approaches may be used for preliminary design, screening purposes or to evaluate earth structure response in case of low seismic excitation levels.

Since earth dams can be quite complex geotechnical structures, the next section will focus on seismic response evaluation by applying some of the outlined analysis procedures to a real case history.

\section{Some issues regarding earth dams}

The structural complexity of earth dams and the high risk associated with them due to major social, economic and environmental consequences of failure, require very reliable analysis tools to study their performance, especially when carrying out a safety assessment involving seismic loads.

Principal damage that earth dams may suffer during an earthquake consists of (Seed, 1979):

- settlements and fractures of the dam body;

- freeboard loss up to the limit of overtopping;

- global instability of upstream and downstream slopes;

- reduction of shear strength up to liquefaction of construction and/or of foundation soils;

- differential displacements between embankment, abutments and spillway;

- failure of outlet works crossing the dam body;

- disruption of dam by major fault movement in foundation;

- overtopping of the dam produced by soil masses sliding into reservoir.

Permanent displacements induced by earthquakes can be considered the integral effect of volumetric and deviatoric plastic strains devel- 


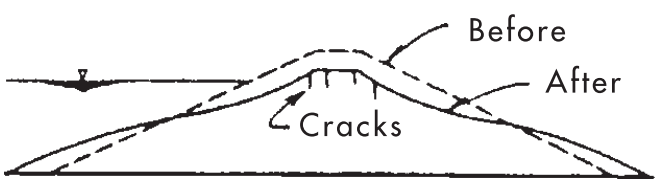

Fig. 5. Typical earthquake-induced damages to earth dams.

oped within the dam embankment. Deviatoric strains produce, as an isolated effect, the so called «lateral spreading» of the dam body. Significant crest settlements produce freeboard loss up to overtopping (fig. 5). Even if this limit is not reached, differential settlements may induce other critical types of damage such as fractures within the dam body, which could then jeopardize the water tightness of the structure.

Global failure induced by earthquakes might occur if the shells are so steep that even static conditions are close to instability. Seismic forces always produce an increase in instability loads and for some soils a decrease of shear strength as well.

The failure mechanism may involve either the dam body and/or the foundation soils.

Other types of damage could derive from strength reduction of soils induced by excess pore water pressure. The latter might cause two different phenomena: liquefaction and cyclic mobility.

Liquefaction consists of a cyclic shear stress process that induces a reduction in strength not compatible with static stability conditions acting at the end of the cyclic process itself. Cyclic mobility refers instead to a similar process where strength reduction is consistent with static stability. Liquefaction induces high deformation in the earth structure even up to collapse either during or after the seismic event. Rapid collapse occurred, for instance, in the Lower San Fernando Dam (1971) and in the Hebgen Dam (1959) several seconds after the end of the earthquake. Liquefaction phenomena occurred also in more than ten small irrigation dams in Akiba (Japan) during the Oga earthquake (1939). In most cases failure occurred some hours after the seismic event.
Cyclic mobility, on the other hand, produces permanent deformations only during the seismic event. Additional plastic strains develop only when shear stresses (static + seismic induced) exceed the soil shear strength. Plastic deformations and related permanent settlements depend on cyclic number and amplitude of shear stresses. Vulnerability to liquefaction of soils used as construction materials depends on the intrinsic soil properties and on the adopted construction technique. It has been observed (Seed, 1979) that hydraulic fill dams are more prone to liquefaction than dams constructed using compaction. Differential movements between dam body, abutments and spillway could cause internal fractures where water could find less resistance to seepage during post-seismic stages, giving rise to so-called «piping». These effects are very difficult to diagnose and are dangerous because piping could progress until abrupt failure of the dam.

\section{The case history of El Infernillo Dam}

The El Infiernillo Dam (fig. 6) has been selected in this study as a case-history sample because it is a high zoned dam $\left(H_{\max }=145 \mathrm{~m}\right)$ located in a highly seismic area (i.e. the Balsas river zone around $300 \mathrm{~km} \mathrm{SW}$ of Mexico City). The region is characterized by significant seismicity fed by the subduction mechanism of the Pacific plate under the American continent.

Since its construction, the El Infiernillo Dam has experienced several earthquakes, among which two strong-motion events (on 14/03/1979 and 19/09/1985). With reference to the earthquakes of 14/03/1979 (Richter magnitude equal to 7.6 and epicentral distance of $134 \mathrm{~km}$ ) and 19/09/1985 (Richter magnitude of 8.1 and epicentral distance of $68 \mathrm{~km}$ ), accelerograms recorded both on the rock abutments of the dam and at reference points along the dam maximum cross section (crest and downstream shell) are available, together with some measurements of earthquake-induced permanent displacements. These field observations have been used in this study to verify the reliability of the selected analysis methods to evaluate the seismic performance of the dam. 

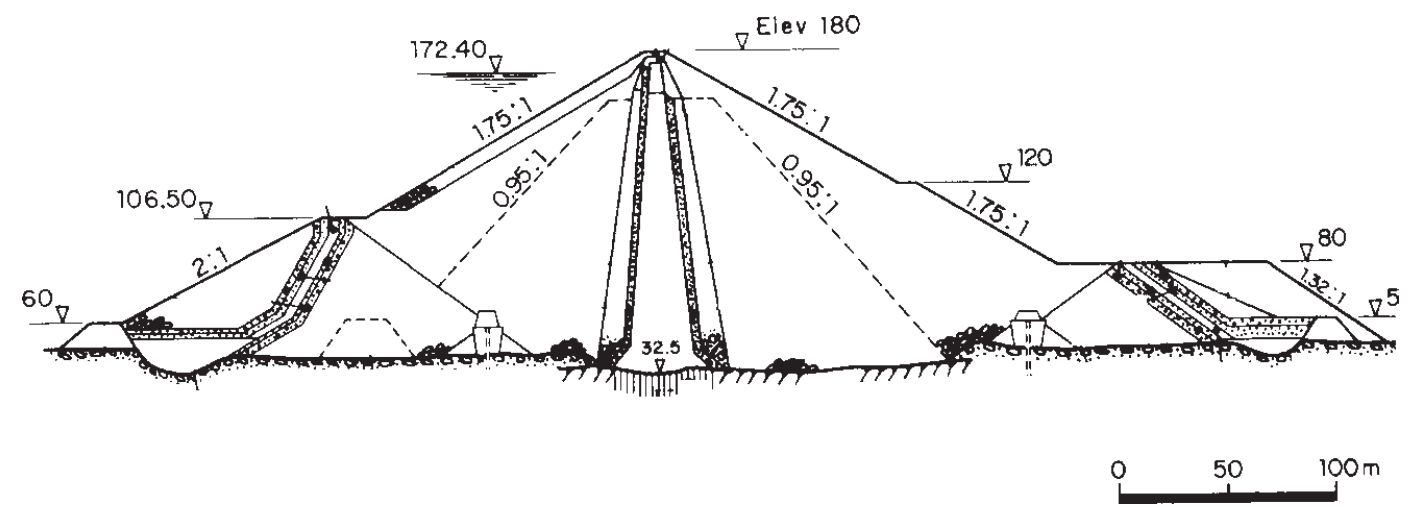

Fig. 6. Main cross section of El Infiernillo Dam.

\subsection{Simplified analysis}

The stability analysis has been performed using the modified Bishop method (Bishop, 1955). The method is based on searching for the safety factor along pre-defined potential circular slip surfaces by a limit equilibrium analysis. A trial and error procedure was adopted to identify the location of the slip surface having the minimum safety factor, both in the upstream and in the downstream rockfill shells of the dam. The pseudostatic inertial forces were assumed to act in an outward direction to sliding (i.e. in the upstream and downstream directions, respectively, for the upstream and downstream shell) in order to maximize the effect of the active forces that induce sliding. The analysis was performed under the hypothesis of steady seepage inside the dam with the reservoir level fixed at its operational maximum. As a consequence, the buoyance unit weight was adopted in the computation regarding the upstream shell, while the actual unit weight of the construction soils was considered in searching for the slip surfaces within the downstream side.

The seismic coefficient was assumed equal to 0.1 , the peak ground acceleration during the $14 / 03 / 1979$ earthquake at the rock base of the dam.

From the two sets of analyses, it appears that higher instability is located in the upstream shell of the structure. Potential sliding surfaces are concentrated in the upper part of the dam close to the external boundary. The minimum safety factor was 1.7, an acceptable value for assuring global stability of the dam.

\subsection{Simplified dynamic analysis}

Among the simplified dynamic methods available in literature, the Newmark approach was selected to evaluate the permanent displacement of the El Infiernillo Dam induced by the 14/03/1979 earthquake.

As indicated before, this method requires the determination of the critical acceleration associated with an assumed sliding surface. The selected surface in this case had the lowest safety factor in the pseudostatic analysis and involved a dangerous failure mechanism involving the overtopping of the reservoir water.

Figure 7 shows the adopted sliding surface for the upstream side of the dam. Figure 8 shows the reduction of the safety factor with increasing seismic coefficient. This plot was obtained by computing the pseudostatic safety factor $\left(S_{F}\right)$ for different values of the seismic coefficient. In correspondence to the unit safety factor $\left(S_{F}=1\right)$, a critical seismic coefficient $\left(k_{c}\right)$ of 0.32 was evaluated. This means that if the average acceleration along the slip surface overtakes the 


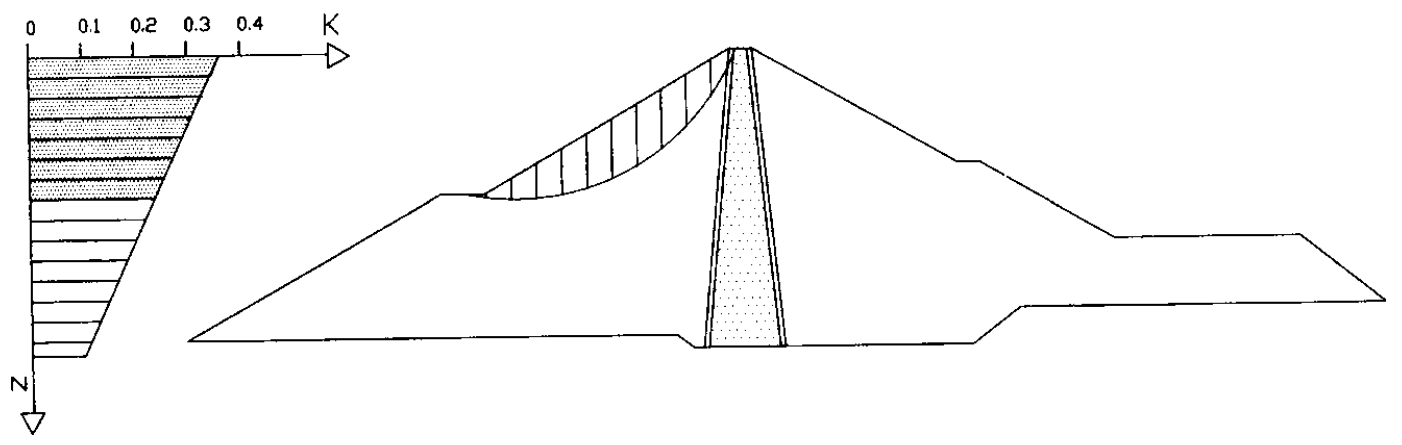

Fig. 7. Sliding surface adopted in the Newmark analysis for the upstream shell of the El Infiernillo Dam.

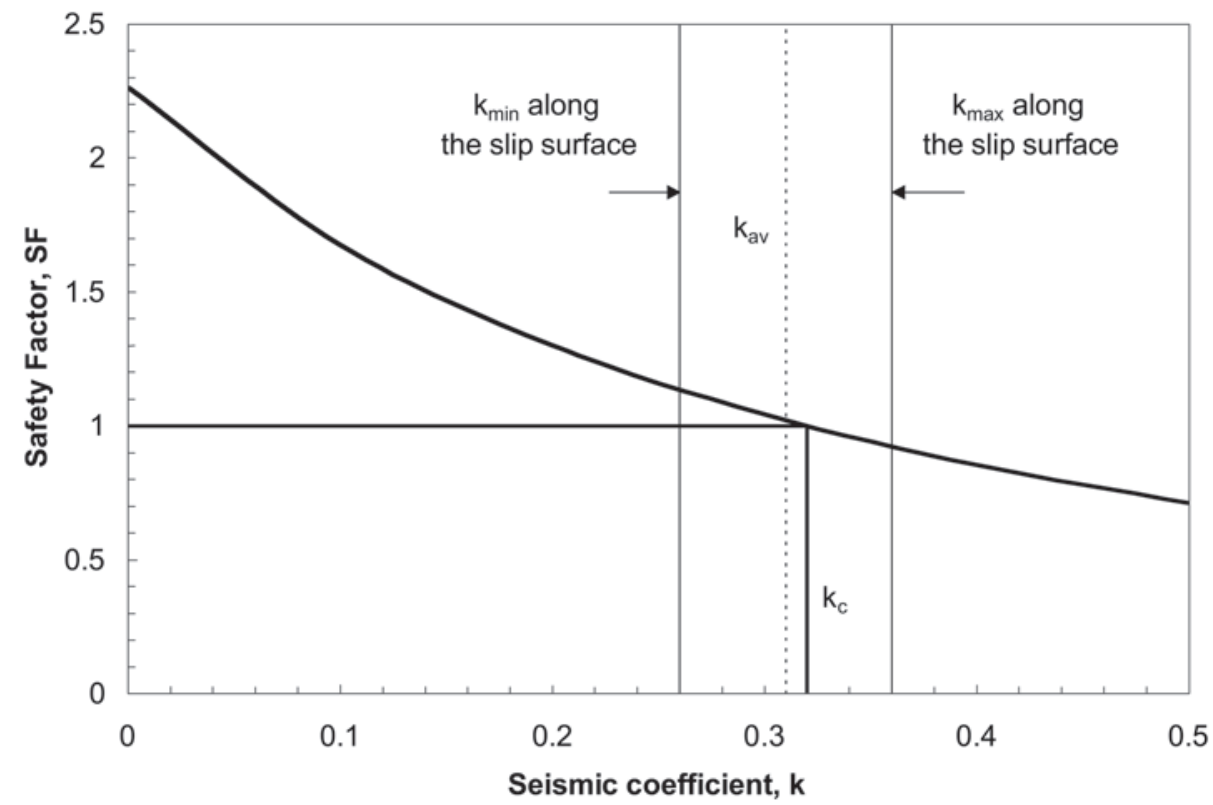

Fig. 8. Pseudostatic safety factor variation with increasing seismic coefficient along the sliding surface.

critical value of $0.32 g\left(a_{\text {crit }}=k_{c} \cdot g\right)$, the sliding mass will start moving as a rigid block.

The left hand side of fig. 7 shows the variation of the peak horizontal acceleration along the dam axis. This plot was obtained by assuming linear variation of acceleration from the measured value of $0.1 \mathrm{~g}$ at the dam base up to the value of $0.36 \mathrm{~g}$ that was recorded at the dam crest during the
14/03/1979 seismic event. Therefore, an average value of $0.31 \mathrm{~g}$ could be reasonably attributed as the unique peak acceleration along the whole sliding surface. Since the driving acceleration is lower than the computed critical acceleration, the Newmark method does not predict any irreversible displacement within the dam. 


\subsection{Full dynamic analysis}

The dynamic analysis was performed using a two-phase coupled approach implemented in the finite element program GEFDYN (Aubry and Modaressi, 1996). The approach is based on the $\boldsymbol{u}-p$ formulation of the Biot generalized consolidation theory (Zienkiewicz and Shiomi, 1984). In particular, the overall dynamic equilibrium and the pore water flow equations were combined with Hujeux's elastoplastic kinematic hardening constitutive law (Hujeux, 1985). This law describes some relevant features of the soil response under monotonic and cyclic loading conditions (hysteresis, liquefaction, cyclic mobility and ratcheting). Since in a coupled effective stress method the predictions of the dynamic analysis are strongly affected by the pre-seismic conditions of stress and pore water pressure distribution within the structure, it was necessary to simulate all stages of the dam's history up until the actual seismic event: construction, first impounding, service operations.

In this study, the model parameters characterizing the materials of the El Infiernillo Dam were evaluated from the laboratory tests performed at the time of dam construction (conventional drained and undrained monotonic triaxial tests and oedometer tests) and on a back-analysis procedure of dam observed behaviour (Sica, 2001). The dam geometry was discretized in about 400 2D quadratic elements (fig. 9). The acceleration time-history used as input motion at the base of the finite element model is the horizontal accelerogram (upstream-downstream direction) recorded on the outcropping rock during the 14/03/1979 earthquake.

At the end of the seismic excitation, the effective stress analysis gives a deformed shape of the dam like that shown in fig. 10. The maximum vertical settlement computed at the end of the earthquake is around $9 \mathrm{~cm}$ at the dam crest; the maximum horizontal displacement in the upstream direction is about $8 \mathrm{~cm}$ and $4 \mathrm{~cm}$ in the downstream direction. These results are consistent with the observed deformed mode of the dam after the same earthquake (Resendiz et al., 1982).

As far as the excess pore water pressures are concerned, the analysis gives a maximum pore

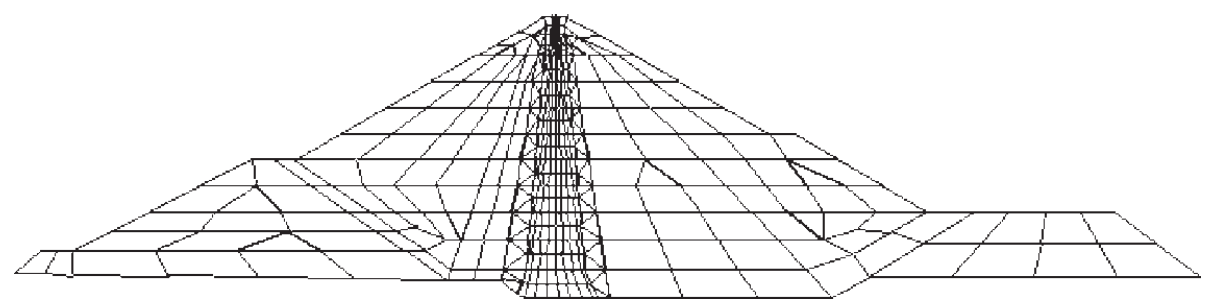

Fig. 9. Mesh geometry of the El Infiernillo Dam adopted in the f.e.m. analysis.

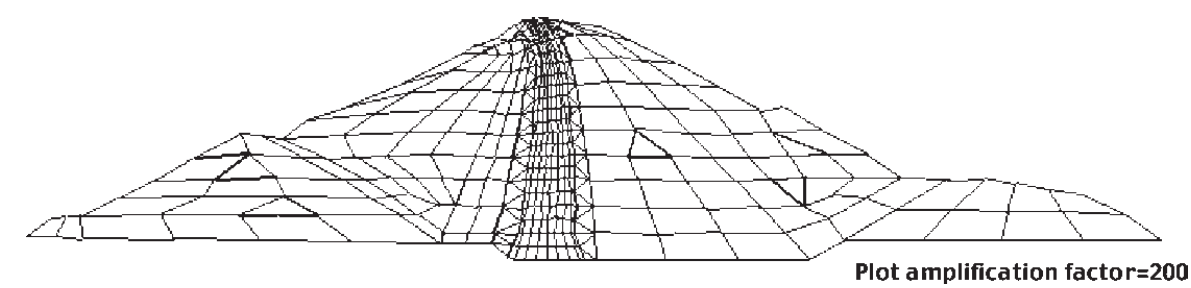

Fig. 10. Deformed mesh geometry of the El Infiernillo Dam after the 14/03/1979 earthquake simulation. 
water pressure ratio $\left(r_{u}=\Delta u / \sigma_{\mathrm{vo}}^{\prime}\right)$ inside the dam body of about $20 \%$, a value far enough from the threshold limit of $100 \%$ at which soil liquefaction may occur.

In conclusion, the effective stress analysis provided the required information about the dam safety in terms of:

1) overtopping: the computed freeboard loss, equal to the seismic induced vertical displacement at the dam top, is only $1 \%$ of the available freeboard $(\approx 10 \mathrm{~m})$;

2) liquefaction: the computed pore water pressure ratio $r_{u}$ is less than $100 \%$;

3) shell stability: the computed horizontal and vertical displacements at the end of the earthquake are very small (less than $10 \mathrm{~cm}$ ) compared to the transverse dimension of the dam.

\section{Conclusions}

To properly analyze the seismic behaviour of geotechnical structures, a complete methodology typically employs several steps. First, a detailed evaluation of the regional seismicity should be performed in order to define the earthquake motion at the base formation where the structure is located. Next, the specific hazard of the site should be assessed by considering either local amplification of ground motion and other problems like soil liquefaction, ground rupture or landslides. Finally, the soil-structure interaction analysis should be performed. Since the whole methodology cannot be described in a single paper, this report focuses only on some relevant aspects of the final step.

The first point highlighted in the paper is a close interconnection between various technical branches (from seismology to geology, engineering and land planning) and government policy in seismic risk analysis. This means that the seismic response of geotechnical structures should be considered just one component of the wider topic of earthquake disaster risk protection and prevention.

The second aspect emphasized in this paper is the importance of proper knowledge of the mechanical properties of the materials constituting the structure and its subsoil. This is a crucial problem for geotechnical engineers because it requires both high technical skill and economic resources for suitable in situ and laboratory investigation.

It was further pointed out that for geotechnical structures, determination of soil properties should be adapted to the analysis method chosen to study seismic response. This choice is not simple, especially if one considers that national standards, except for some specific and recent releases, are usually not exhaustive on the safety evaluation of structures under seismic actions. In general, they account for the amplification of the ground motion due to site conditions in a very rough manner, and suggest only simplified analysis methods.

Conventional approaches provide information on the structure's capacity to resist a design seismic force, but they are not able to predict structural performance during and after the earthquake. The performance-based design approach, first developed for buildings, is nowadays proposed for geotechnical structures as well. A comprehensive report on this topic, oriented towards port structures, can be found in International Navigation Association (2001). Extracted from that report are the following points:

1) deformations in ground and foundation soils, together with corresponding structural deformation and stress states, are key design parameters;

2) conventional limit equilibrium-based methods are not well-suited to evaluate these parameters, and

3) some residual deformation may be acceptable.

In performance-based design, appropriate levels of design earthquake motions must be defined along with acceptable levels of structural damage. For design purposes, two levels of earthquake motions are typically used:

- Level L1: earthquake motion that is likely to occur during the life-span of the structure (probability of exceeding is $50 \%$ ).

- Level L2: earthquake motion associated with rare events that typically involve very strong ground shaking (probability of exceeding is $10 \%$ ).

The acceptable level of damage is set according to some specific structural (predicted amount of damage) and operational (level of loss 
of serviceability, time and cost for restoration) factors.

Once the design earthquake levels and acceptable damage levels have been properly defined, the required performance of a structure may be represented by a performance grade determined by the importance of the structure (critical and key structures, primary structures, ordinary structures and small, easily restorable structures).

The principal steps taken in performancebased design are summarized in the flowchart of fig. 11.

It is apparent that for geotechnical structures, appropriate damage criteria should be related to the deformation mode of the structure itself. As a consequence, sophisticated analyses should be adopted to model structure performance adequately.
In this paper, the seismic behaviour of an earth dam was analyzed as a sample geotechnical structure. Even if this case history was examined from a verification rather than design viewpoint, the study is very explanatory of the capability of a coupled dynamic analysis in predicting structure performance during and after a selected earthquake. In particular, this type of analysis method allows forecasting of seismically induced displacements in the dam body with good accuracy, as verified by comparing analytical results with monitoring data. Figure 12 reports the computed vertical displacements profiles at three locations along the dam axis. On the right side hand of the figure the residual displacements are plotted together with the measured ones, showing good agreement between the analysis prediction and observed behaviour.

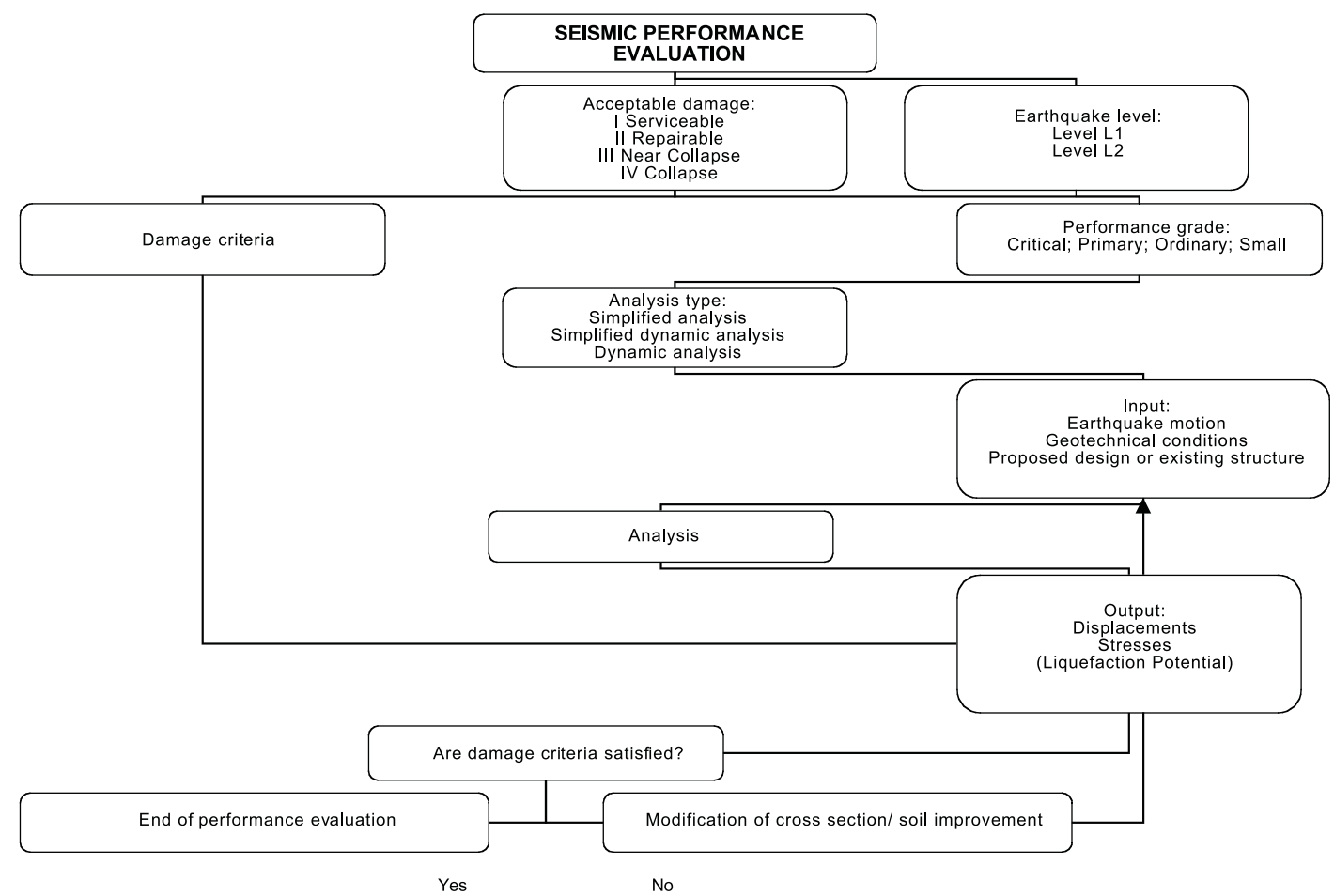

Fig. 11. Steps required for the seismic behaviour analysis of a geotechnical structure using a performance-design based approach (modified after International Navigation Association, 2001). 


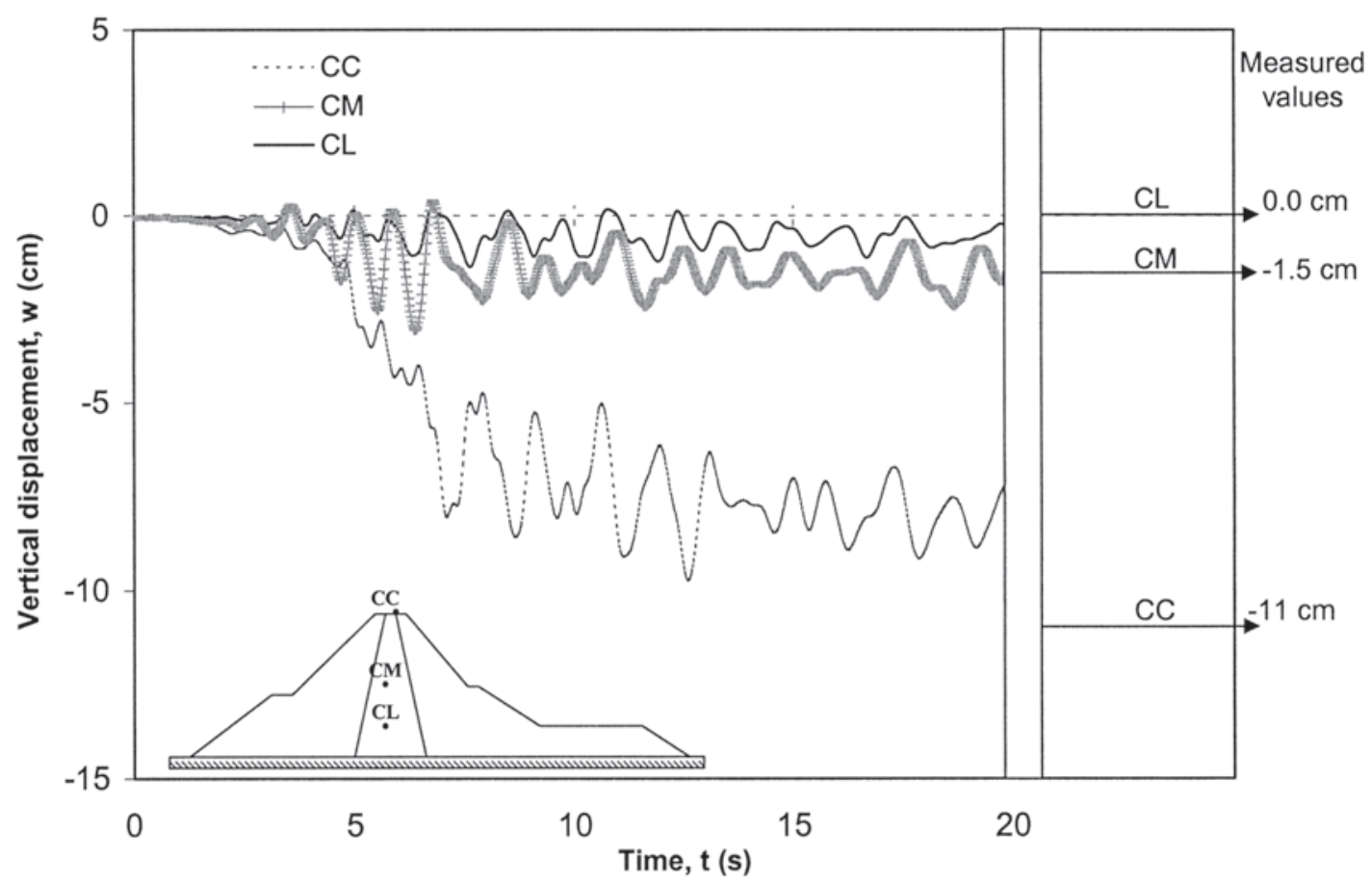

Fig. 12. Time histories of vertical displacement at three points along the dam axis.

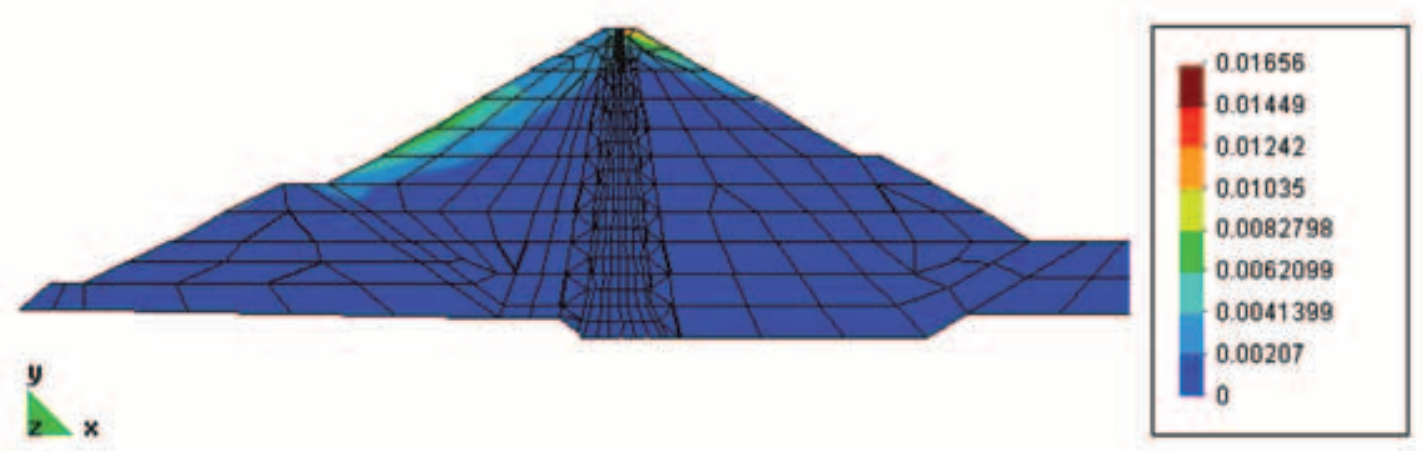

Fig. 13. Contour plot of plastic shear strains at the end of the 14/03/1979 earthquake.

It is worth emphasizing that while the pseudostatic method does not directly predict displacements, no seismically-induced movements were forecast by the simplified dynamic analyses using the Newmark method. In any case, the critical slip surface given by the pseudostatic approach, found by trial and error, lies very close to the area in which maximum plastic shear deformations were detected by the full dynamic analysis (fig. 13). 


\section{Acknowledgements}

The authors wish to give thanks to Prof. $\mathrm{H}$. Akihama, Nihon University, and Prof. A. Rapolla, University of Naples, scientific organizers of the Kyoto and Kobe meeting, for offering us the opportunity to contribute our findings in a high level meeting that was useful for exchanging opinions with several experts in the area of natural disaster mitigation. A vote of thanks should be given to Prof. M. Nakashima and his staff at Kyoto University for the tremendous effort in organizing the symposium; to Dr. A. Volpi, scientific attaché at the Italian Embassy in Japan and the Italian Embassy in Japan, for the care and the support received; to Mr. M. Di Gianni, Honorary Consul of Japan in Naples, and to all participants in the symposium for their friendship and frank exchange of ideas.

\section{REFERENCES}

AUBry, D. and A. ModARESSI (1996): GEFDYN, Manuel Scientifique, Ecole Centrale de Paris (in French).

BENZENATI, I. (1993): Modeling of dynamic behaviour of saturated soils applied at dams and site effects, Ph.D. Thesis, Ecole Centrale de Paris (in French).

BisHOP, A.W. (1955): The use of the slip circle in the stability analysis of slopes, Geotechnique, 5 (1), 7-17.

Cavallaro, A., V. Fioravante, G. Lanzo, D.C.F. Lo PRESTI, O. PAllara, S. RAMPEllo, A. D'ONOFRIO, F. SANTUCCI DE MAGISTRIS and F. Silvestri (2001): Report on the current situation of laboratory stress-strain testing of geomaterials in Italy and its use in practice, in Advanced Laboratory Stress-Strain Testing of Geomaterials, edited by F. TATSUOKA, S. SHIBUYA and R. KUWANO (Swets and Zeitlinger Publishers Lisse, Netherlands), 15-44.

DAVIDSON, R. (1997): An urban earthquake disaster risk index, The John A. Blume Earthquake Engineering Center, Report n. 121, Stanford, California, Blume Center.

D'ONOFRIO, A. and F. Silvestri (2001): Influence of microstructure on small strain stiffness and damping of fine graded soils and effects on local site response, in Fourth International Conference on Recent Advances in Geotechnical Earthquake Engineering and Soil Dynamics, March 2001, San Diego, California.

Di BENEDETTO, H., F. TATSUOKA and M. IshiHARA (2002): Time-dependent shear deformation characteristics of sand and their constitutive modelling, Soils and Foundation, 42 (2), 1-22.

Dobry, R., W.G. PIERCE, R. DYviK, G.E. Thomas and R.S LADD (1985): Pore pressure model for cyclic straining of sand, Internal report, Civil Engineering Dept. Rensselaer Polytechnic Institude Troy, New York.
FINN, W.D.L. and S.K. BATHIA (1981): Prediction of seismic porewater pressures, in Proceedings of the Tenth International Conference on Soil Mechanics and Foundation Engineering (Balkema, Rotterdam), vol. 3, 201-206.

FINN, W.D.L., M. YogendRAKUMAR, N. YOSHIDA and H. YOSHIDA (1986): TARA-3: a program to compute the response of $2 D$ embankments and soil structure interaction systems to seismic loadings, Department of Civil Engineering, University of British Columbia, Vancouver, Canada.

FOTI, S. (1999): Multistation methods for geotechnical characterization using surface waves, Ph.D. Thesis, Politecnico di Torino.

FrankLin, A.G. and F.K. ChAnG (1977): Earthquake resistance of earth and rockfill dams, Report 5: permanent displacements of earth dams by Newmark analysis, US Army Corps of Engineers, Waterways experiments Station, Miscellaneous Paper, 2-71-17.

HujeuX, J.C. (1985): Une loi de comportement pour le chargement cyclique des sols, in Genie Parasismique, edited by V. DAVIDOVICI (Presses ENCP), 287-302 (in French).

IAI, S., K. ICHII, H. LIU and T. MORITA (1998): Effective stress analyses of port structures, Special issue on Geotechnical Aspects of the January 17, 1995 HyogokenNambu Earthquake, Soils and Foundation, 2, 97-114.

IDRISS, I.M., J. LYSMER, R. HWANG and H.B. SEED (1973): QUAD-4: a computer program for evaluating the seismic response of soil structures by variable damping finite element procedures, Report n. EERC 73-16, Earthquake Engineering Research Center, University of California, Berkeley.

INTERNATIONAL NAVIGATION ASSOCIATION (2001): Seismic Design Guideline for Port Structures, Working Group n. 34 of the Maritime Navigation Commission (Swets and Zeitlinger Publishers Lisse, Netherlands).

KRAMER, S.L. (1996): Geotechincal Earthquake Engineering (Prentice Hall Inc., New Jersey), pp. 653.

KUWANO, J. and M. KATAGIRI (2001): Recent state of laboratory stress-strain tests and geomaterials in Japan, in Advanced Laboratory Stress-Strain Testing of Geomaterials, edited by F. TATSUOKA, S. SHIBUYA and R. KuWANO (Swets and Zeitlinger Publishers Lisse, Netherlands), 47-52.

LYSMER, J., T. UDAKA, C.F. TSAI and H.B. SEED (1975): FLUSH: a computer program for approximate $3 D$ analyses of soil-structure interaction, Report EERC 7530, Earthquake Engineering Research Center, University of California, Berkeley.

MAKDISI, F.I. and H.B. SEED (1978): Simplified procedure for estimating dam and embankment earthquake-induced deformations, ASCE, J. Geotech. Eng. Div., 104 (GT7), 849-867.

MARTIN, G.R., W.D.L. FinN and H.B. SEED (1975): Fundamentals of liquefaction under cyclic loading, ASCE, J. Geotech. Eng. Div., 101 (GT5), 423-438

MatASOVIC, N. and M. VuCETIC (1992): A pore pressure model for cyclic straining of clay, Soils and Foundation, 32 (3), 156-173

Matasovic, N. and M. VuCETIC (1995): Generalized cyclic- 
degradation-pore pressure generation model for clays, ASCE, J. Geotech. Eng. Div., 121 (1), 33-42.

MONONOBE, N. (1924): Consideration on vertical earthquake motion and relevant vibration problems, J. Jpn. Soc. Civ. Eng., 10 (5), 1063-1094.

MuraleEtharan, K.K., C. Mish, K. YogachandRAn and K. ARULANANDAN (1988): DYSAC2: dynamic soil analysis code for 2-dimensional problems, Department of Civil Engineering, University of California, Davis.

NEWMARK, N.M. (1965): Effects of earthquakes on dams and embankments, Geotechnique, 15 (2), 139-160.

OKABE, N. (1924): General theory on earth pressure and seismic stability of retaining walls and dams, J. Jpn. Soc. Civ. Eng., 10 (6), 1277-1323.

Ozutsumi, O., K. YuU, M. Kiyama and S. Iai (2000): Residual deformation analysis of sheetpile quay wall and backfill ground at Showa-Ohashi site by simplified method, in Proceedings of 12th World Conference on Earthquake Engineering, Auckland (Balkema, Rotterdam).

PREVOST, J.H. (1985): Wave propagation in fluid-saturated porous media: an efficient finite element procedure, Soil Dyn. Earthquake Eng., 4 (4), 183-202

Resendiz, D., M.P. Romo and E. Moreno (1982): El Infiernillo and La Villita Dams: seismic behaviour, ASCE, J. Geotech. Eng. Div., 108 (GT1), 109-131.

RICHARDS, R. JR. and D. ELMS (1979): Seismic behavior of gravity retaining walls, ASCE, J. Geotech. Eng. Div., 105 (GT4), 449-464

Santucci de Magistris, F., J. Koseki, M. Amaya, S. HAMAYA, T. SATO and F. TATSUOKA (1999): A triaxial testing system to evaluate stress-strain behaviour of soil for wide range of strain and strain rate, ASTM, Geotech. Testing J., 22 (1), 44-60.

SCHNABEL, P.B, L. LYSMER and H.B. SEED (1972): SHAKE: a computer program for earthquake response analysis of horizontally layered sites, UCB/EERC-72/12, Earthquake Engineering Research Center, University of California, Berkeley, December 1972.

SiCA, S. (2001): Dynamic analysis of earth dams, Ph.D. Thesis, Università degli Studi di Napoli «Federico II» (in Italian).

SiCA, S., L. PAGANO and A. Modaressi (2001): Numerical simulation of the El Infiernillo Dam response by a coupled dynamic approach, ASCE, J. Geotech. Geoenviron. Eng. (submitted).

SEED, H.B. (1979): Considerations in the earthquake-resistant design of earth and rockfill dams, Geotechnique, 29 (3), 215-263.

STEEDMAN, R.S. (1998): Seismic design of retaining walls, Geotechical Engineering, Proc. Inst. Civ. Eng., 131, 12-22.

SteinbrugGe, K.V. and W. Cloud (1962): Epicentral intensities and damages in the Hebgen Lake, Montana earthquake of August 17, 1959, Bull. Seismol. Soc. Am, 52 (2), 118-234.

TATSUOKA, F., T. SATO, C.-S. PARK, Y.-S. KiM, J.N. MUKABI and Y. KoHATA (1994): Measurements of elastic properties of geomaterials in laboratory compression tests, ASTM, Geotech. Testing J., 17 (1), 80-94.

TATSUOKA, F., F. SANTUCCI DE MAGISTRIS, K. HAYANO, Y. MOMOYA and J. KOSEKI (2000): Some new aspects of time effects on the stress-strain behaviour of stiff geomaterials, in 2nd International Conference of Hard Soils and Soft Rock, Napoli October 1998, edited by A. EVANGELISTA and L. PICARELLI (Balkema, Rotterdam), vol. 3, 1285-1371.

TAtsuoka, F., M. Ishihara, H. Di Benedetto and R. KUWANO (2002): Time-dependent shear deformation characteristics of geomaterials and their simulation, Soils and Foundation, 42 (2), 103-129.

TOWHATA, I. and S. IsLam (1987): Prediction of lateral movement of anchored bulkheads induced by seismic liquefaction, Soils and Foundation, 27 (4), 137-147.

Vinale, F., A. D'ONOFRIO and F. SANTUCCI DE MAGISTRIS (2000): Recent development in geotechnical experiments, in 20th Conference of the Italian Geotechnical Association, Parma September 1999, Riv. Ital. Geotec., 3, 38-69 (in Italian).

Vinale, F., A. D'Onofrio, C. Mancuso, F. SANTUCCI DE MAGISTRIS and F. TATSUOKA (2001): The pre-failure behaviour of soils as construction materials, in $2 n d$ International Symposium on Pre-failure Deformation Characteristics of Geomaterials, IS Torino, Italy, 28-30 September 1999, edited by M. JAMIOLKOWSKI, R. LANCELLOTTA and D. LO PRESTI (Balkema, Rotterdam), vol. 2, 955-1007.

YEGIAN, M.K., E. MARCIANO and V.G. GHARAMAN (1991) Earthquake-induced permanent deformation: probabilistic approach, ASCE, J. Geotech. Eng., 29 (1), 93 104.

ZIENKIEWICZ, O.C. and T. SHIOMI (1984): Dynamic behaviour of saturated porous media; the generalised Biot formulation and its numerical solution, Int. J. Num. Anal. Methods Geomech., 8, 71-96. 